\title{
Diagnostic performance of CMR, SPECT, and PET imaging for the detection of cardiac amyloidosis: a meta-analysis
}

Zhaoye Wu and Chunjing Yu*

\begin{abstract}
Background: Noninvasive myocardial imaging modalities, such as cardiac magnetic resonance (CMR), single photon emission computed tomography (SPECT), and Positron emission tomography (PET), are well-established and extensively used to detect cardiac amyloid (CA). The purpose of this study is to directly compare CMR, SPECT, and PET scans in the diagnosis of CA, and to provide evidence for further scientific research and clinical decision-making.

Methods: PubMed, Embase, and Cochrane Library were searched. Studies used CMR, SPECT and/or PET for the diagnosis of CA were included. Pooled sensitivity, specificity, positive and negative likelihood ratio (LR), diagnostic odds ratio (DOR), their respective 95\% confidence intervals (Cls) and the area under the summary receiver operating characteristic (SROC) curve (AUC) were calculated. Quality assessment of included studies was conducted.
\end{abstract}

Results: A total of 31 articles were identified for inclusion in this meta-analysis. The pooled sensitivities of CMR, SPECT and PET were $0.84,0.98$ and 0.78 , respectively. Their respective overall specificities were $0.87,0.92$ and 0.95 . Subgroup analysis demonstrated that ${ }^{99 \mathrm{~m} T c-H M D P}$ manifested the highest sensitivity (0.99). ${ }^{99 \mathrm{~m}} \mathrm{Tc}$-PYP had the highest specificity (0.95). The AUC values of ${ }^{99 \mathrm{~m} T C-D P D,}{ }^{99 m} \mathrm{Tc}-P Y P,{ }^{99 \mathrm{~m}} \mathrm{Tc}-\mathrm{HMDP}$ were $0.89,0.99$, and 0.99 , respectively. PET scan with ${ }^{11} \mathrm{C}-\mathrm{PIB}$ demonstrated a pooled sensitivity of 0.91 and specificity of 0.97 with an AUC value of 0.98 .

Conclusion: Our meta-analysis reveals that SEPCT scans present better diagnostic performance for the identification of CA as compared with other two modalities.

Keywords: Cardiac amyloidosis, Noninvasive imaging, Radionuclide, Diagnostic performance, Meta-analysis

\section{Background}

Cardiac amyloidosis (CA) is a myocardial disease characterized by abnormal extracellular deposition of amyloid fibrils, which gives rise to a progressive structural and functional damage to the cardiac tissue $[1,2]$. CA is the main cause of death and occurrence in systemic amyloidosis [3]. On the basis of the underlying nosology, two subtypes (systemic light chain (AL) amyloidosis and transthyretin (ATTR) amyloidosis) account for most cases of

*Correspondence: ycjwxd1978@jiangnan.edu.cn Department of Nuclear Medicine, Affiliated Hospital of Jiangnan University, Wuxi, China cardiac amyloid. The two types of amyloidosis possess different clinical presentations and prognosis $[4,5]$.

The diagnostic approaches of cardiac amyloidosis include clinical symptoms, laboratory tests, non-invasive imaging, and histopathological diagnosis [6]. Unfortunately, this disease is commonly asymptomatic over a period of time from the beginning and the symptoms are usually nonspecific, and therefore its diagnosis is often delayed [2]. Currently, the gold standard for the diagnosis of CA is endomyocardial biopsy [7]. Nevertheless, endomyocardial biopsy is an invasive modality which can lead to unwanted complications. Echocardiography is widely employed for the diagnosis of CA in patients 
with suspected amyloidosis in clinical settings, however, it does not differentiate ATTR from AL CA [8]. It is reported that the diagnostic accuracy of echocardiography in combination with electrocardiogram (ECG) findings is only $60 \%$ [9]. Cardiac magnetic resonance (CMR) imaging is a mature and advanced imaging approach to describe the morphological characteristics and function of the heart and determine the characteristics of cardiac tissue, however, it may be in lack of specificity in distinguishing the potential causes of different types of CA and holds important prognostic information [5, 10, 11]. Molecular imaging is another type of noninvasive modality for the diagnosis of CA. The favorable efficacy of technetium (Tc)-99m labelled bone seeking tracers in single photon emission computed tomography (SPECT) (pyrophosphate $\left({ }^{99 \mathrm{~m}} \mathrm{Tc}-\mathrm{PYP}\right), 3$, 3-diphosphono-1,2-propanodicarboxylic acid ( $\left.{ }^{99 \mathrm{~m}} \mathrm{Tc}-\mathrm{DPD}\right)$, and hydroxymethylene diphosphonate $\left.{ }^{99 \mathrm{~m}} \mathrm{Tc}-\mathrm{HMDP}\right)$ ) for diagnosing CA have been manifested in several studies [12-14]. Furthermore, positron emission tomography (PET) scans with tracers including ${ }^{11} \mathrm{C}$-Pittsburgh compound B (PIB), ${ }^{18} \mathrm{~F}$-florbetapir, ${ }^{18} \mathrm{~F}$-florbetaben, ${ }^{18} \mathrm{~F}-\mathrm{NaF}$, and ${ }^{18} \mathrm{~F}$-flutemetamol have been studied for cardiac amyloidosis [15-18]. Compared to SPECT, PET shows higher spatial resolution and may provide more accurate quantification of absolute tracer uptake [5, 14].

As far as we are concerned, accumulated studies and meta-analyses have evaluated diagnostic performance of non-invasive modalities for the confirmation of CA [12, 19-23]. Most of these meta-analyses are on singlemodality basis. The aim of this study was to generate a more comprehensive comparison of CMR, SPECT, and PET in the identification of CA by pooling the data of available studies, and subsequently to provide updated evidence-based information and hints for not only scientific research but also for the implement and decisionmaking of clinical practitioners.

\section{Methods}

This meta-analysis was conducted strictly on the basis of the Preferred Reporting Items for Systematic Reviews and Meta-analysis (PRISMA) [24]. Details on each procedure of the study were reported as follows.

\section{Search strategy and study selection}

The researchers did a comprehensive search of the electronic databases: PubMed, Embase, and Cochrane Library from January 1, 2011 to November 30, 2020, only

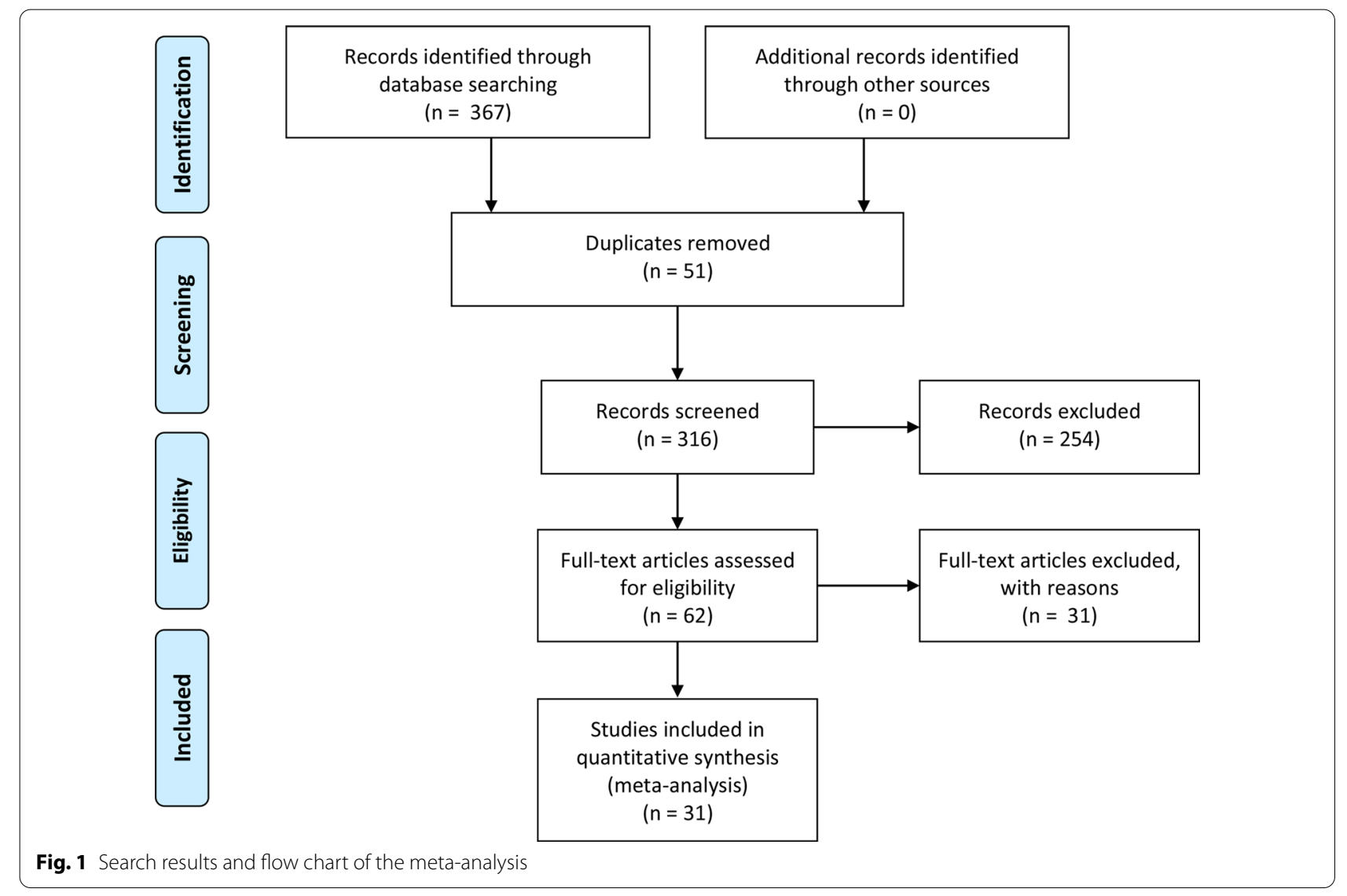




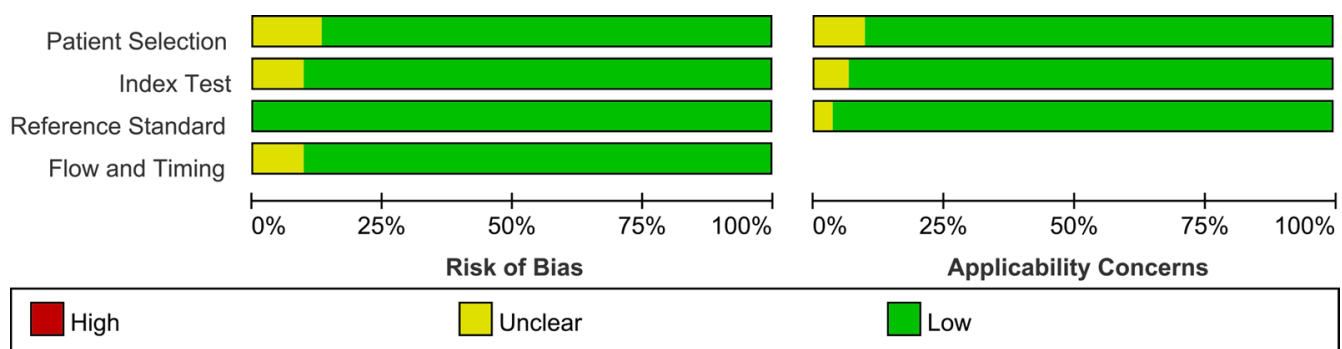

Fig. 2 Risks of bias and applicability concerns on the QUADAS-2 tool of the enrolled studies

articles in the English language were considered. The following key words or phrases were used for the database research: "cardiac magnetic resonance", "CMR", "singlephoton emission computed tomography", "SPECT", "positron emission tomography", "PET", "Cardiac amyloidosis" and "CA". The references of these articles were also searched for potential eligible researches. The inclusion criteria of this meta-analysis were as follows: (a) CMR, SPECT and/or PET were employed for the detection of CA in patients with suspected or diagnosed CA; (b) specific gold standard reference was used to evaluate the diagnostic performance; (c) absolute numbers of patients with true positive (TP), false positive (FP), true negative $(\mathrm{TN})$ and false negative (FN) outcomes were depicted directly in the original article or the references or all these numbers could be calculated based on the articles. In case that the studies were carried out by the same research team, only those with the largest sample size or the most complete information were included. Studied without necessary parameters mentioned above, case reports, reviews, letters to the editorial, conference abstracts, and animal studies were not taken into account in the meta-analysis.

Two authors independently conducted the database search and study selection. Discrepancies were resolved by discussion until a final decision was reached.

\section{Data extraction and quality assessments}

Two reviewers independently performed the screening of types of articles, titles and abstracts according to the protocol of study selection, hereafter the full-text reading of the articles was conducted for the final inclusion. The following information was retrieved from each study included: name of first author, year of publication, number of patients analyzed, reference standard, type of detection modalities and type of radiopharmaceuticals used in the study, absolute number of participants with TP, TN, FP and FN results. Quality Assessment of Diagnostic Accuracy Studies-2 (QUADAS-2) criteria was used to assess the quality of each included studies, this quality scale includes components in terms of participant selection, index test, reference standard, as well as flow and timing [25]. Any disagreements occurred in the process of data extraction and quality assessments were resolved by consensus.

\section{Statistical analysis}

Data were analyzed employing the Stata version 15.0 software and Review Manager version 5.3 software at the study level. A $p$ value $<0.05$ was considered to be statistically significant. We calculated pooled sensitivity, specificity, positive and negative likelihood ratio (LR), diagnostic odds ratio (DOR), and their respective 95\% confidence intervals (CIs) and the area under the summary receiver operating characteristic (SROC) curve (AUC). The Cochran $\mathrm{Q}$ and the $\mathrm{I}^{2}$ statistics were introduced to assess the heterogeneity of studies included on qualitative and quantitative basis. $\mathrm{I}^{2}$ values within $0-25 \%$, $25-50 \%, 50-75 \%$, and $75-100 \%$ manifested insignificant, low, moderate, and high heterogeneity, respectively [26]. Funnel plots were conducted to qualitatively assess potential bias of publication, A Deeks' method was used to statistically test the asymmetry of the funnel plots and detect publication bias [27]. Moreover, we used sensitivity analysis to evaluate the impacts of each single study on the pooled outcomes.

\section{Results}

\section{Study selection and characteristics}

A total of 367 articles were identified from the databases searched. Among them, 51 duplicates were removed and 254 studies were excluded through an initial screening. After a full text assessment for eligibility of the remaining62 articles, 31 articles with 37 studies and 2585 patients with confirmed or suspected CA were identified for inclusion in this meta-analysis. The articles of Gillmore et al. and Kircher et al. reported performance evaluation of 3 modalities, respectively. The publications of Lee et al. and Minamimoto et al. reported results of 2 imaging tools, respectively. No additional studies 


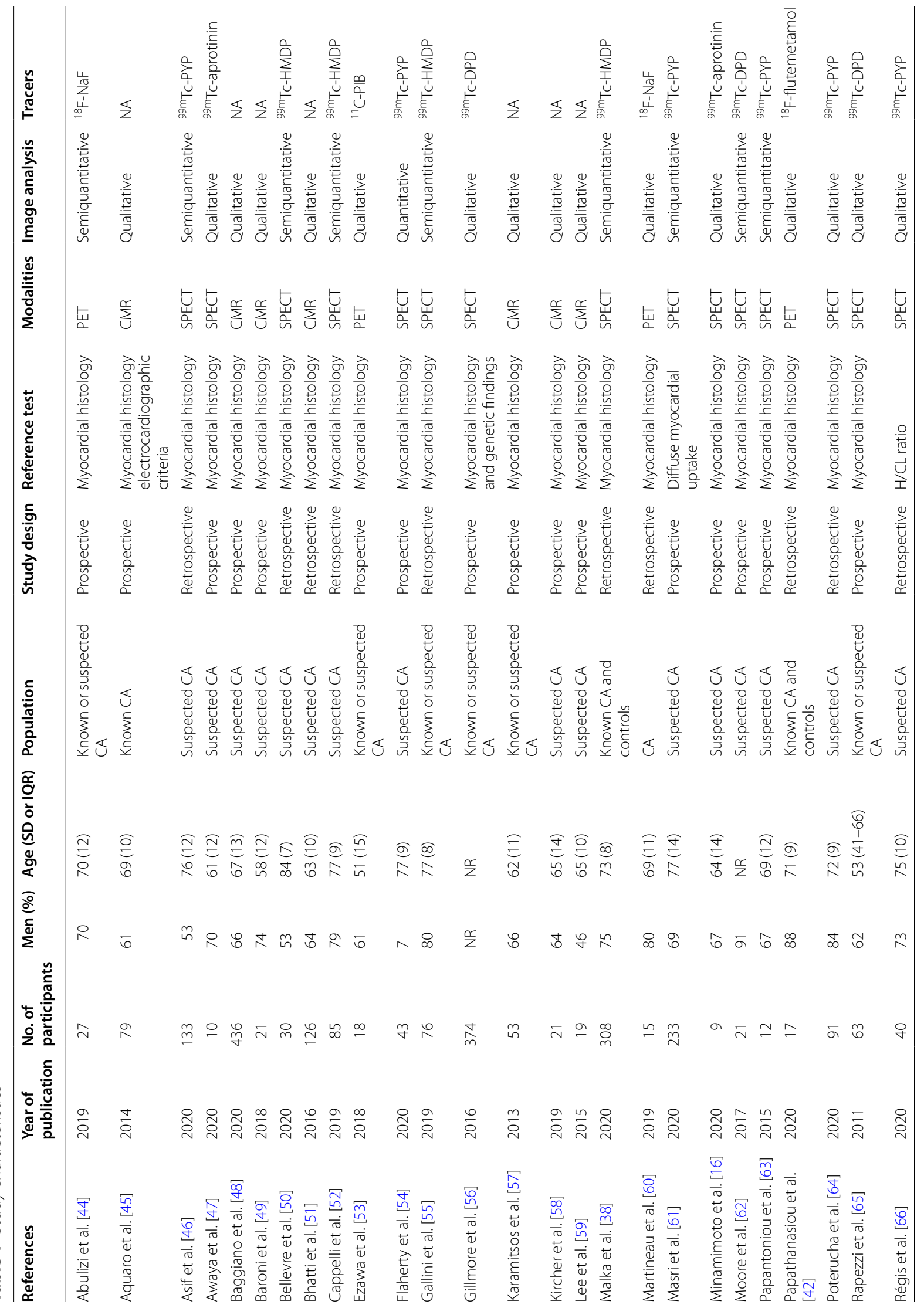




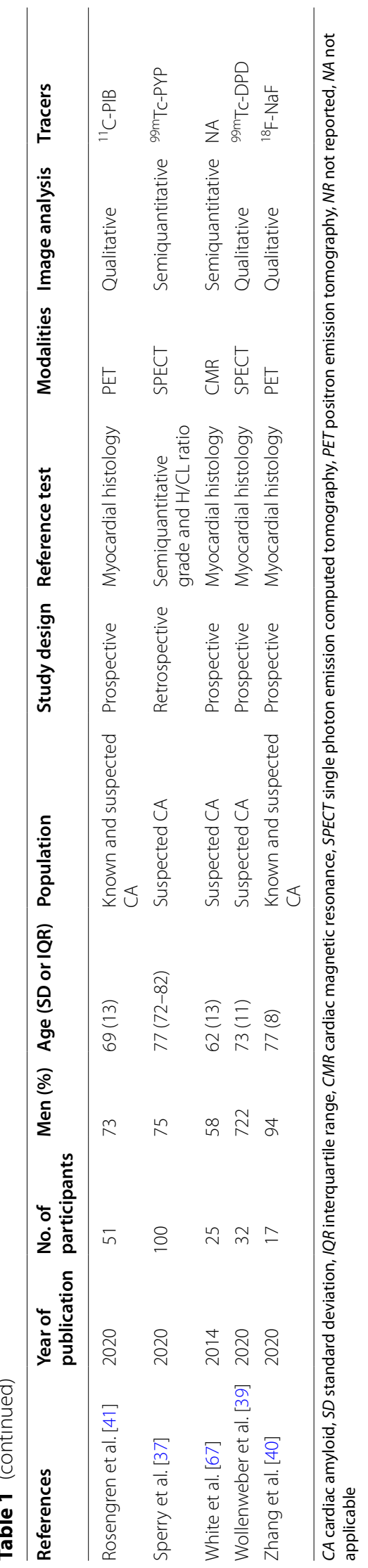




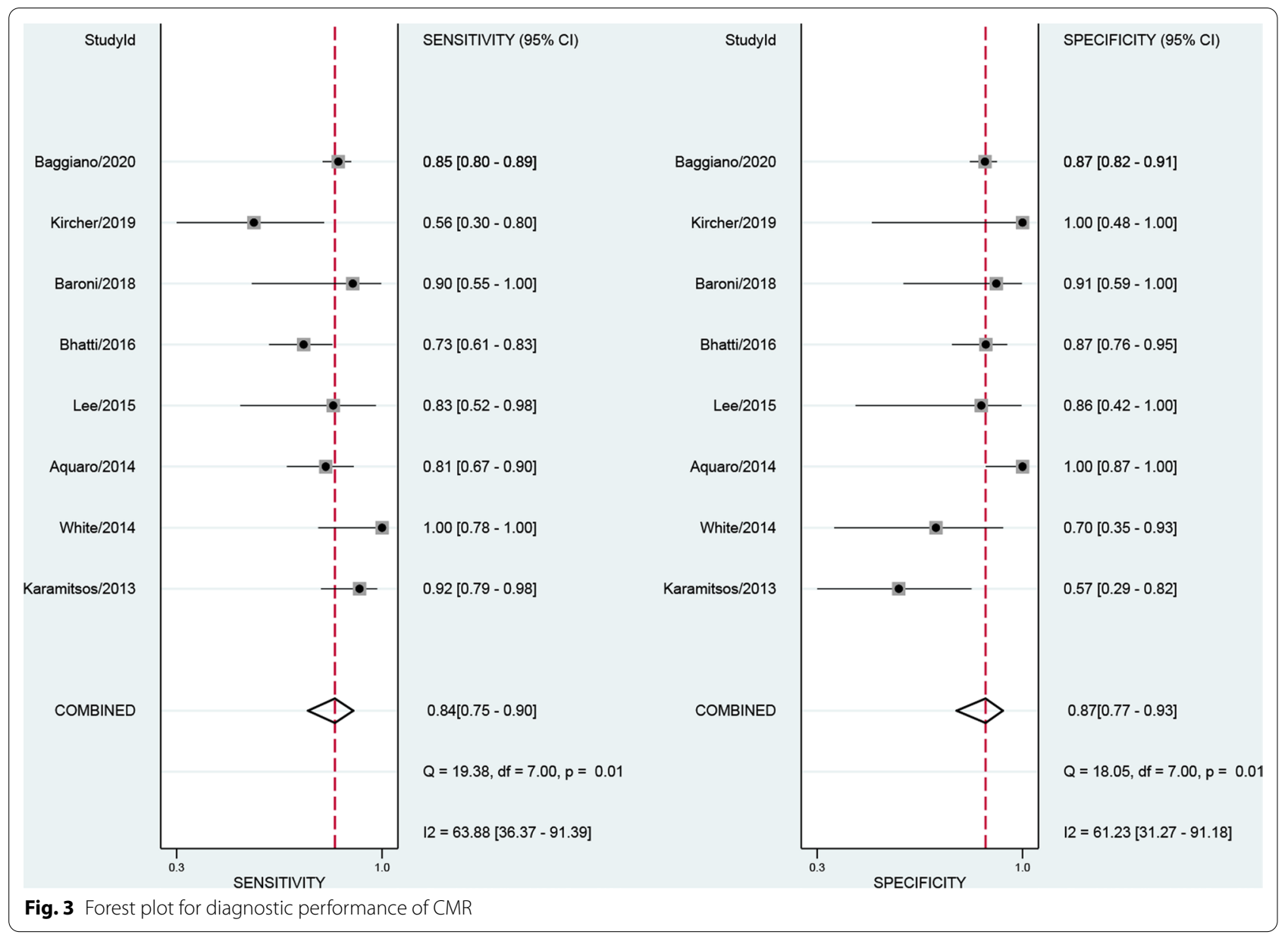

were found through reference screening of the included papers. Figure 1 shows the flow of the database search and literature selection process. The quality of the included studies was regarded as high according to the QUADAS-2 scale (Fig. 2). Table 1 details the characteristics of studies included.

\section{Diagnostic performance of noninvasive modalities}

The numbers of studies included in the analysis of CMR, SPECT and PET were 8, 20 and 9, respectively. The pooled sensitivity of CMR, SPECT and PET were 0.84 $[0.75,0.90], 0.98[0.94,0.99]$ and $0.78[0.54,0.92]$, respectively. The overall specificities were 0.87 [0.77, 0.93], 0.92 $[0.83,0.97]$ and $0.95[0.85,0.98]$ for CMR, SPECT and PET, respectively (Figs. 3, 4, 5). The AUC values of CMR, SPECT and PET were 0.92 [0.89, 0.94], 0.99 [0.98, 1.00] and $0.95[0.93,0.96]$.

\section{Diagnostic performance of prospective studies}

With regard to prospective studies of these detection approaches, the respective overall sensitivities of CMR, SPECT and PET were 0.85 [0.76, 0.91], 0.98 [0.90, 0.99] and $0.85[0.63,0.95]$. The pooled specificities were 0.89 [0.72, 0.96], $0.87[0.73,0.94]$ and $0.98[0.68,1.00]$ for CMR, SPECT and PET, respectively (Additional file 1: Figure S1, Additional file 2: Figure S2, Additional file 3: Figure S3). The AUC values of CMR, SPECT and PET were $0.92[0.89,0.94], 0.97[0.96,0.98]$ and 0.98 [0.97, 0.99].

\section{Subgroup analysis of SPECT tracers}

The numbers of studies using ${ }^{99 \mathrm{~m}} \mathrm{Tc}-\mathrm{DPD},{ }^{99 \mathrm{~m}} \mathrm{Tc}-\mathrm{PYP}$, ${ }^{99 \mathrm{~m}} \mathrm{Tc}-\mathrm{HMDP}$, and ${ }^{99 \mathrm{~m}} \mathrm{Tc}$-aprotinin for SPECT radiotracers were $5,8,5$, and 2, respectively. Studies using ${ }^{99 \mathrm{~m}} \mathrm{Tc}$-aprotinin were not enrolled in pooled analysis for the inadequate number of studies. Overall results demonstrated that ${ }^{99 \mathrm{~m}} \mathrm{Tc}-\mathrm{HMDP}$ manifested the highest sensitivity $(0.99[0.83,1.00]) .{ }^{99 \mathrm{~m}} \mathrm{Tc}-\mathrm{PYP}$ had the highest pooled specificity $(0.95[0.86,0.99])$. The pooled sensitivity of ${ }^{99 \mathrm{~m}} \mathrm{Tc}-\mathrm{DPD}$ and ${ }^{99 \mathrm{~m}}$ Tc-PYP reached 0.98 (Additional file 4: Figure S4, Additional file 5: Figure S5, Additional file 6: Figure S6). The AUC values of ${ }^{99} \mathrm{~m}$ TcDPD, ${ }^{99 m}$ Tc-PYP, ${ }^{99 m} \mathrm{Tc}-H M D P$ were 0.89 [0.86, 0.92], $0.99[0.98,1.00]$, and $0.99[0.98,1.00]$, respectively. 


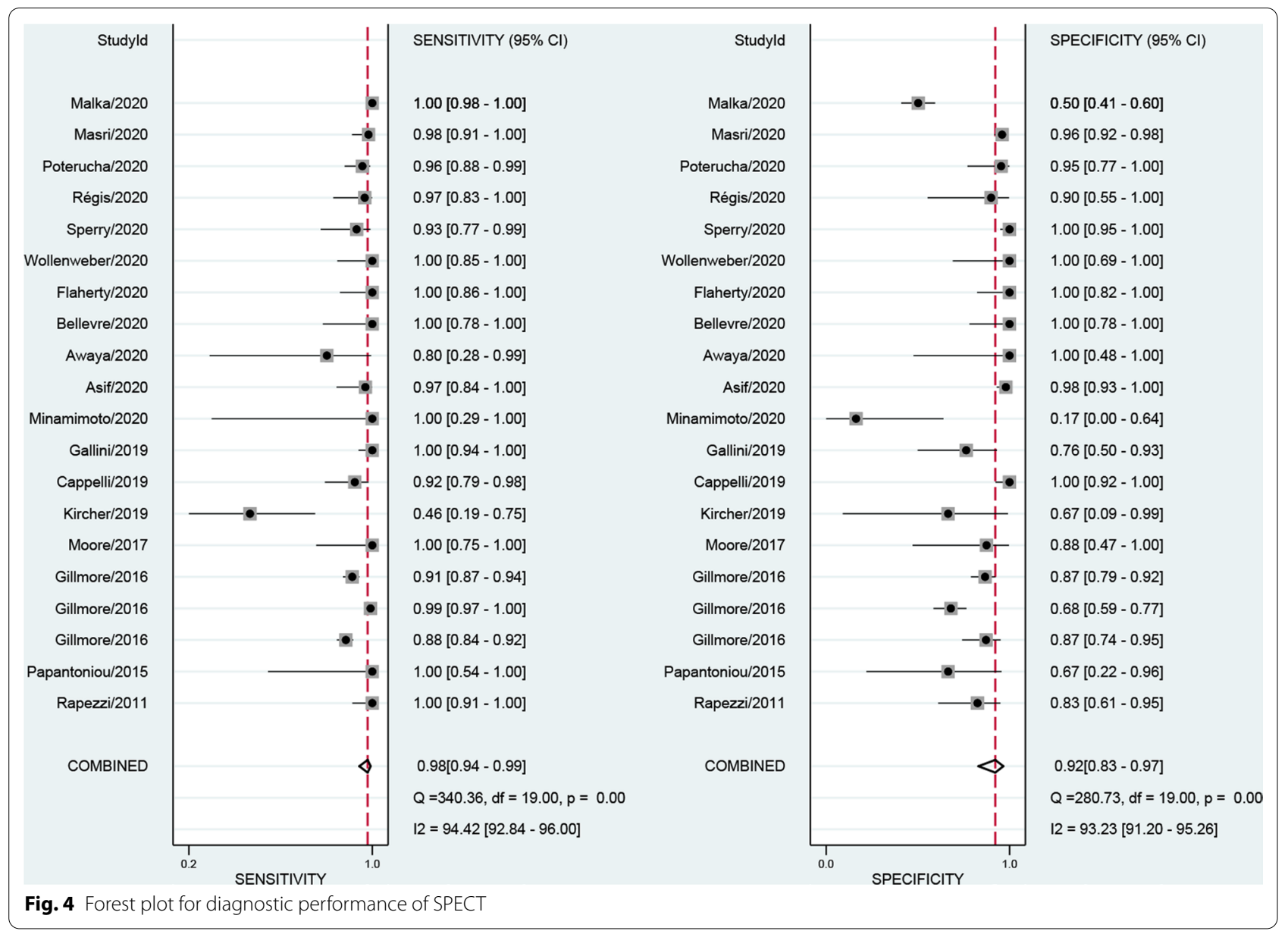

\section{Subgroup analysis of PET tracers}

The number of included studies using ${ }^{11} \mathrm{C}$-PIB, ${ }^{18} \mathrm{~F}$-florbetaben, ${ }^{18} \mathrm{~F}$-flutemetamol, and ${ }^{18} \mathrm{~F}-\mathrm{NaF}$ for PET tracers were $4,1,1$, and 3 , respectively. Only PET studies utilizing ${ }^{11} \mathrm{C}$-PIB were included in pooled analysis. It demonstrated a pooled sensitivity of 0.91 [0.81, 0.96], and its pooled specificity was 0.97 [0.81, 1.00] (Additional file 7: Figure S7). The AUC value of ${ }^{11} \mathrm{C}$-PIB was 0.98 [0.97, 0.99 ]. Both the reported sensitivity and specificity of ${ }^{18} \mathrm{~F}$-florbetaben PET for the separation of patients with CA from patients without CA were $100 \%$.The study of ${ }^{18} \mathrm{~F}$-flutemetamol showed a sensitivity of 0.17 with a high proportion of false-negative PET results.

\section{Heterogeneity and publication bias}

The $\mathrm{I}^{2}$ values for meta-analysis of CMR were 64 (pooled sensitivity) and 61 (pooled specificity). The respective $\mathrm{I}^{2}$ static for SPECT were 94 and 93. As for PET, the $\mathrm{I}^{2}$ values for pooled analysis of sensitivity and pooled specificity were 85 and 31. Deek's funnel plot asymmetry tests for publication bias yielded $\mathrm{p}$ values of $0.89,0.88$, and 0.08 for CMR, SPECT and PET, which revealed that there may be no potential publication bias in the study (Fig. 6).

\section{Sensitivity analysis}

Sensitivity analysis was conducted to assess the potential influence of single study on the overall results. After omitting each study one by one, the pooled results of CMR, SPECT, PET and the corresponding subgroup analysis remained robust (Additional file 8: Figure S8, Additional file 9: Figure S9, Additional file 10: Figure S10).

\section{Discussion}

CA is part of systemic amyloidosis, it's characterized by the abnormal accumulation of amyloid fibrils within the extracellular of the myocardial tissue [28]. Accurate and timely confirmation of CA is of particular importance because cardiac involvement usually can be lethal [29]. Endomyocardial biopsy remains the gold standard for the detection and evaluation of prognosis of CA [30]. However, it's an invasive method and introduces potential damage to human body [31, 32]. Among those 


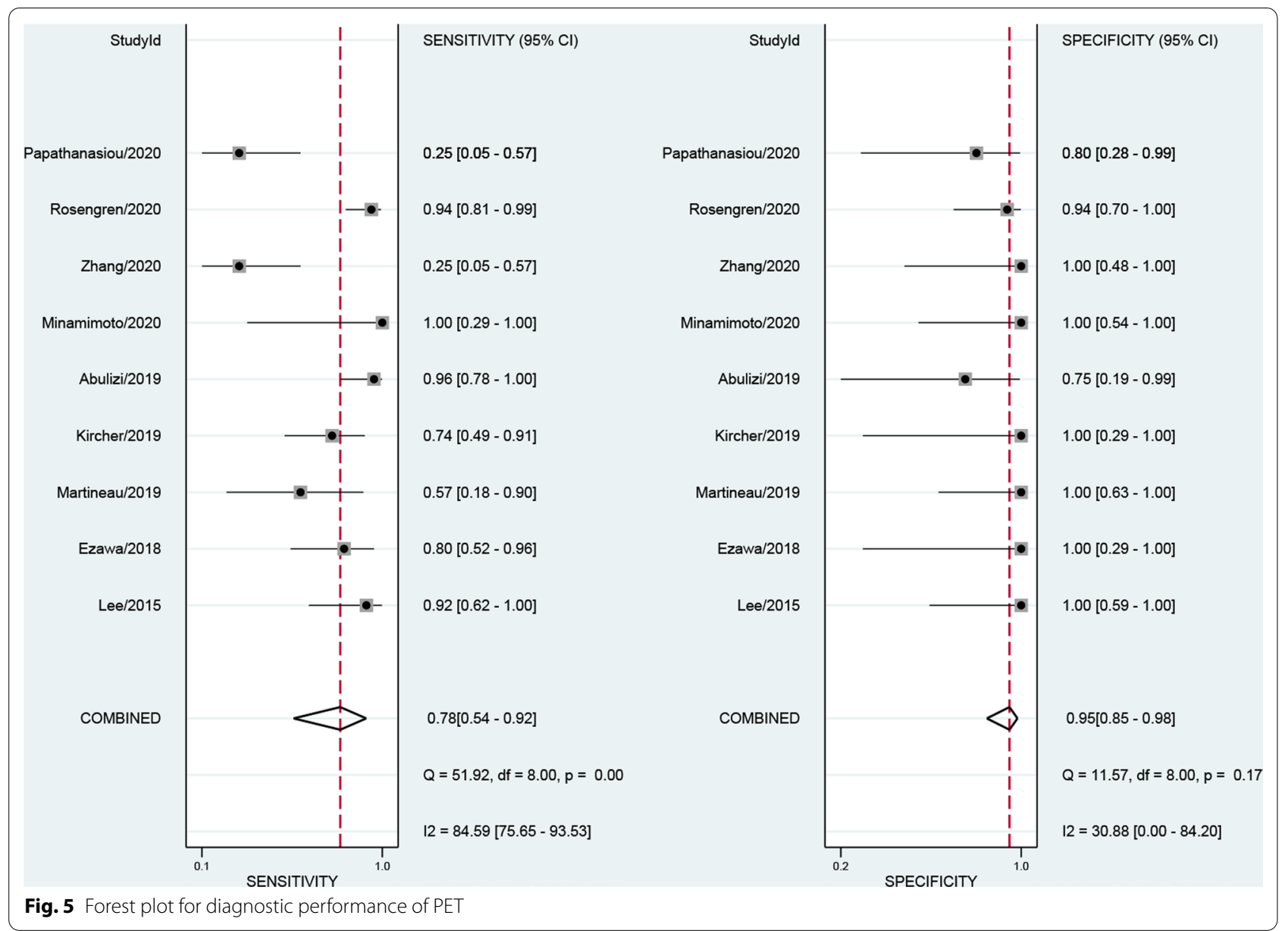

noninvasive modalities, cardiac ultrasound is widely used, but the diagnostic accuracy is relatively low, and it is clinically used to identify potential patients with CA and further workup should be conducted [33, 34]. It is reported that CMR manifested favorable sensitivity and specificity in the identification of CA regardless of its low cost-effectiveness $[10,35]$. The increase in myocardial extracellular volume (ECV) is readily detected by CMR via the Late Gadolinium Enhancement (LGE) test, which demonstrated a sensitivity of $80 \%$ and a specificity of $90 \%$ in detecting CA $[34,36]$. Furthermore, the administration of SPECT scans with ${ }^{99 \mathrm{~m}} \mathrm{Tc}-\mathrm{DPD},{ }^{99 \mathrm{~m}} \mathrm{Tc}$-PYP, ${ }^{99 \mathrm{~m}} \mathrm{Tc}-$ HMDP revealed promising results [37-39]. Compared with SPECT, PET showed higher spatial resolution, it has been represented as a promising approach in the field of CA diagnosis [40-42]. In clinical setting, each single or the combination employment of the above cardiac imaging approaches need to be explained together with the other clinical findings. The imaging techniques not only help to diagnose $\mathrm{CA}$, but also help to estimate the type and the severity of the disease, provide prognostic markers of the disease and monitor the effectiveness of therapy [43]. This meta-analysis is focused on the role of the first of these steps: diagnosis of CA.

Previous meta-analysis commonly focused on single diagnosis tool of CA [19, 21-23]. We conducted a metaanalysis to directly compare the performance of CMR, SPECT and PET for the diagnosis of CA. The analysis was on the updated articles with respect to study design, type of radiotracers in SPECT and PET scans. This is one of the strengths of this study. It is worth noting 20 of the total 31 articles included in this meta-analysis were published in the years of 2019 and 2020, which indicated that noninvasive diagnostic modalities especially SPECT and PET scans have been extensively investigated. In general, results of this meta-analysis revealed that CMR, SPECT, 
A

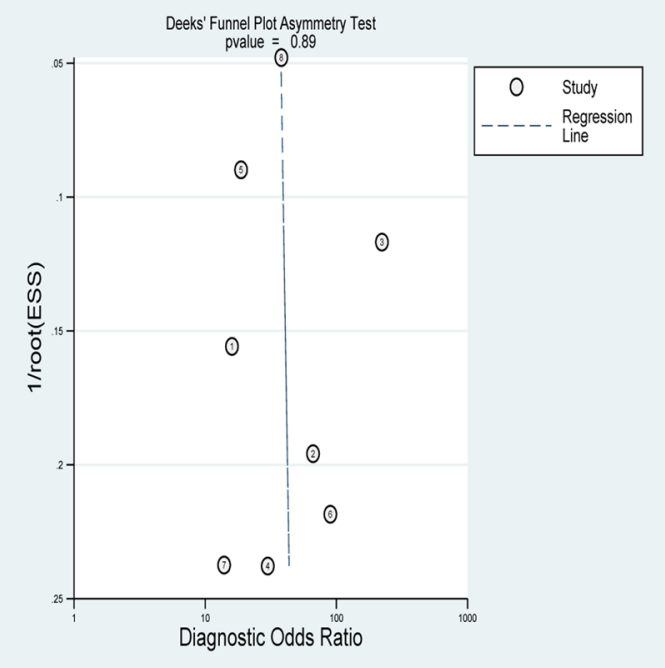

B

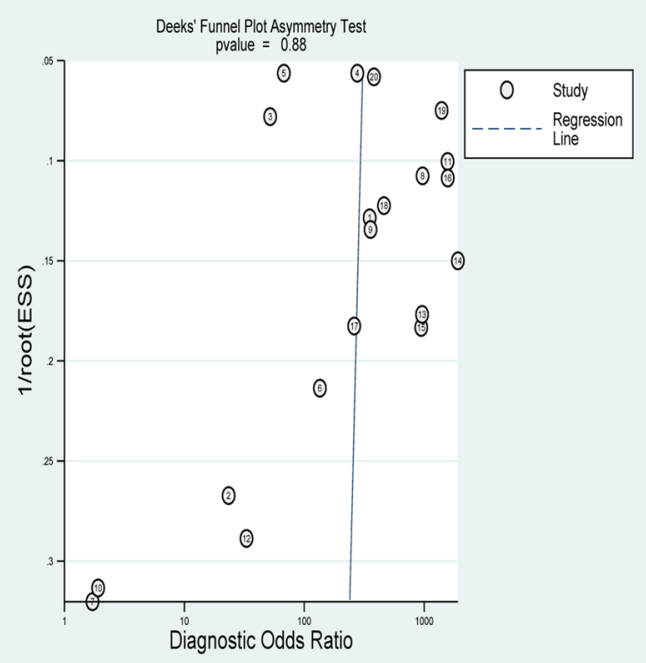

$\mathrm{C}$

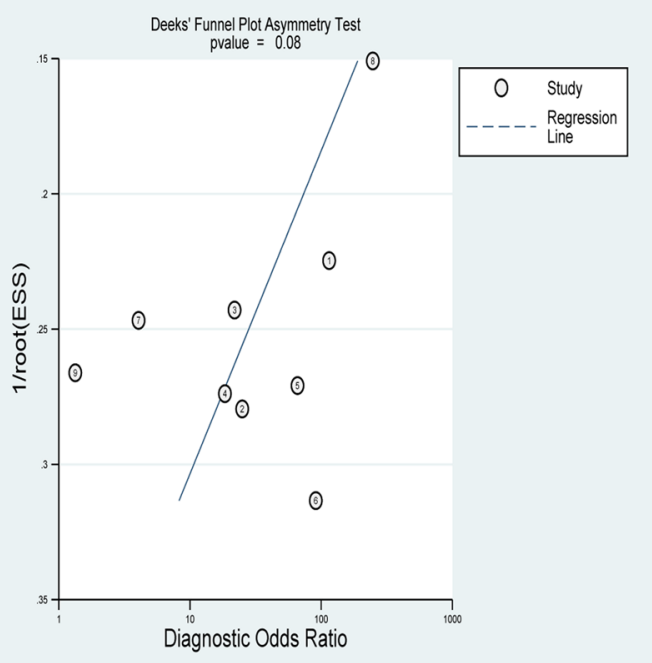

Fig. 6 Funnel plots for diagnostic performance of CMR, SPECT and PET. A Funnel plot for diagnostic performance of CMR. B Funnel plot for diagnostic performance of SPECT. C Funnel plot for diagnostic performance of PET

and PET presented high sensitivity and specificity for the diagnosis of CA. The pooled sensitivity $(0.98[0.94,0.99])$ of SPECT scan was the highest. PET manifested the highest pooled specificity $(0.95[0.85,0.98])$. The AUC values of CMR, SPECT and PET were 0.92 [0.89, 0.94], $0.99[0.98,1.00]$ and $0.95[0.93,0.96]$, respectively. When prospective studies were considered, overall sensitivity of SPECT was still the highest $(0.98[0.90,0.99])$. Interestingly, PET scans showed the highest specificity (0.98 $[0.68,1.00])$. On the basis of this difference in results, we can make a preliminary conclusion that the study design could be the source of heterogeneity of enrolled studies. Besides, results manifested ${ }^{99 \mathrm{~m}} \mathrm{Tc}-\mathrm{HMDP}$ had the highest sensitivity $(0.99[0.83,1.00]),{ }^{99 \mathrm{~m}} \mathrm{Tc}-\mathrm{PYPhad}$ the highest pooled specificity $(0.95[0.86,0.99]) .{ }^{99 \mathrm{~m}} \mathrm{Tc}-\mathrm{PYP}$ and ${ }^{99 m}$ Tc-HMDP revealed good diagnostic performance with AUC values of 0.99 [0.98, 1.00] and 0.99 [0.98, 1.00], respectively. As for PET scans, PET studies using ${ }^{11} \mathrm{C}$-PIB was included in pooled analysis, both the pooled sensitivity and specificity reached more than 0.90 , the AUC 
value of was surprisingly 0.98 . One study reported that the sensitivity and specificity of ${ }^{18} \mathrm{~F}$-florbetaben PET for the detection of CA were $100 \%$, the level of evidence in this study was relatively lower than a meta-analysis, and therefore a possibly pooled analysis of PET scans using ${ }^{18} \mathrm{~F}$-florbetaben is recommended in the future.

In this meta-analysis, we comprehensively searched the online database to enhance the possibility of retrieving as more eligible studies as we could. Two researchers independently performed the whole process of information extraction under the guidance of the study protocol. Moreover, the heterogeneity across the studies included was assessed using Cochran Q test. In general, there existed significant heterogeneities among studies. The sources of heterogeneity may be attributed to difference in the year of publication, study design (as mentioned above), and patient characteristics. We indented to conduct meta-regression to explore the possible origins of heterogeneity, unfortunately, the numbers of PET and CMR studies were insufficient to complete meta-regression. The underlying sources of heterogeneity would be investigated in further studies. Moreover, results of sensitivity analysis claimed that after omitting individual study one after another, the pooled indicators were robust in this study. The Deek's funnel plot asymmetry tests for publication bias revealed that there may not be publication bias in the meta-analysis. Despite the existence of heterogeneity, we may conclude based on the pooled results that this analysis could provide evidence-based information for scientific research and practical applications in the process of CA diagnosis. As far as scientific research is concerned, prospective studies and PET radiotracers with higher spatial resolution need to be further investigated on the basis of results of this meta-analysis. Meta-analysis with larger sample-sized and amount of studies are recommended. With regard to applications in clinical settings, decision-making of practitioners in the diagnosis of CA should be made according to technical merit, consideration of cost-effectiveness, and the availability of specific modalities. In order to enhance diagnostic accuracy of $\mathrm{CA}$, if possible, the combination of different diagnostic tools is recommended.

\footnotetext{
Abbreviations

CA: Cardiac amyloidosis; AL: Systemic light chain amyloidosis; ATTR: Transthyretin amyloidosis; CMR: Cardiac magnetic resonance; SPECT: Single photon emission computed tomography; PET: Positron emission tomography; CT: Computerized tomography; PRISMA: Preferred Reporting Items for Systematic Reviews and Meta-analysis; TP: True positive; FP: False positive; TN: True negative; FN: False negative; PPV: Positive predictive value; NPV: Negative predictive value; DOR: Diagnostic odds ratio; Cl: Confidence interval; SROC: Summary receiver operating characteristic; AUC: Area under the SROC curve; QUADAS-2: Quality Assessment of Diagnostic Accuracy Studies-2; LGE: Late Gadolinium Enhancement.
}

\section{Supplementary Information}

The online version contains supplementary material available at https://doi. org/10.1186/s12872-021-02292-z.

Additional file 1. Forest plot for diagnostic performance of CMR in prospective studies Forest plot for diagnostic performance of CMR in prospective studies.

Additional file 2. Forest plot for diagnostic performance of SPECT in prospective studies Forest plot for diagnostic performance of SPECT in prospective studies.

Additional file 3. Forest plot for diagnostic performance of PET in prospective studies Forest plot for diagnostic performance of PET in prospective studies.

Additional file 4. Forest plot for diagnostic performance of 99mTc-DPD SPECT Forest plot for diagnostic performance of ${ }^{99 \mathrm{~m}} \mathrm{Tc}$-DPD SPECT.

Additional file 5. Forest plot for diagnostic performance of 99mTc-PYP SPECT Forest plot for diagnostic performance of ${ }^{99 \mathrm{~m} T C-P Y P ~ S P E C T . ~}$

Additional file 6. Forest plot for diagnostic performance of 99mTc-HMDP SPECT Forest plot for diagnostic performance of ${ }^{99 \mathrm{~m} T C-H M D P ~ S P E C T . ~}$

Additional file 7. Forest plot for diagnostic performance of 11C-PIB PET Forest plot for diagnostic performance of ${ }^{11} \mathrm{C}$-PIB PET.

Additional file 8. Results of sensitivity analysis of CMR imaging Results of sensitivity analysis of CMR imaging.

Additional file 9. Results of sensitivity analysis of SPECT imaging Results of sensitivity analysis of SPECT imaging.

Additional file 10. Results of sensitivity analysis of PET imaging Results of sensitivity analysis of PET imaging.

Acknowledgements

Not applicable.

Authors' contributions

ZW conceived and designed this study. ZW and CY were responsible for the collection, extraction, and analysis of the data. ZW was responsible for data analysis and writing the paper. CY performed the quality evaluation of the writing and polished the English language. Both authors read and approved the final manuscript.

Funding

There is no fund support for this study.

Availability of data and materials

The datasets used and/or analysed during the current study are available from the corresponding author on reasonable request.

\section{Declarations}

Ethics approval and consent to participate

Not applicable.

Consent for publication

Not applicable.

Competing interests

The authors declare that they have no competing interests.

Received: 13 June 2021 Accepted: 17 September 2021

Published online: 07 October 2021

References

1. Merlini G, Bellotti V. Molecular mechanisms of amyloidosis. N Engl J Med. 2003:349(6):583-96. 
2. Martinez-Naharro A, Hawkins PN, Fontana M. Cardiac amyloidosis. Clin Med (Lond). 2018;18(Suppl 2):s30-5.

3. Fontana M, Banypersad SM, Treibel TA, Abdel-Gadir A, Maestrini V, Lane T, Gilbertson JA, Hutt DF, Lachmann HJ, Whelan CJ, et al. Differential myocyte responses in patients with cardiac transthyretin amyloidosis and light-chain amyloidosis: a cardiac MR imaging study. Radiology. 2015;277(2):388-97.

4. Zhang KW, Stockerl-Goldstein KE, Lenihan DJ. Emerging therapeutics for the treatment of light chain and transthyretin amyloidosis. JACC Basic Transl Sci. 2019;4(3):438-48.

5. Bhogal S, Ladia V, Sitwala P, Cook E, Bajaj K, Ramu V, Lavie CJ, Paul TK. Cardiac amyloidosis: an updated review with emphasis on diagnosis and future directions. Curr Probl Cardiol. 2018:43(1):10-34.

6. Singh V, Falk R, Di Carli MF, Kijewski M, Rapezzi C, Dorbala S. State-ofthe-art radionuclide imaging in cardiac transthyretin amyloidosis. J Nucl Cardiol. 2019;26(1):158-73.

7. Bokhari S, Shahzad R, Castaño A, Maurer MS. Nuclear imaging modalities for cardiac amyloidosis. J Nucl Cardiol. 2014;21(1):175-84.

8. Yang M, Arsanjani R, Roarke MC. Advanced nuclear medicine and molecular imaging in the diagnosis of cardiomyopathy. AJR Am J Roentgenol. 2020;215(5):1208-17.

9. Austin BA, Tang WH, Rodriguez ER, Tan C, Flamm SD, Taylor DO, Starling RC, Desai MY. Delayed hyper-enhancement magnetic resonance imaging provides incremental diagnostic and prognostic utility in suspected cardiac amyloidosis. JACC Cardiovasc Imaging. 2009;2(12):1369-77.

10. Maceira AM, Joshi J, Prasad SK, Moon JC, Perugini E, Harding I, Sheppard MN, Poole-Wilson PA, Hawkins PN, Pennell DJ. Cardiovascular magnetic resonance in cardiac amyloidosis. Circulation. 2005;111(2):186-93.

11. Martinez-Naharro A, Treibel TA, Abdel-Gadir A, Bulluck H, Zumbo G, Knight DS, Kotecha T, Francis R, Hutt DF, Rezk T, et al. Magnetic resonance in transthyretin cardiac amyloidosis. J Am Coll Cardiol. 2017;70(4):466-77.

12. Treglia G, Glaudemans A, Bertagna F, Hazenberg BPC, Erba PA, Giubbini R, Ceriani L, Prior JO, Giovanella L, Slart R. Diagnostic accuracy of bone scintigraphy in the assessment of cardiac transthyretin-related amyloidosis: a bivariate meta-analysis. Eur J Nucl Med Mol Imaging. 2018;45(11):1945-55

13. Ramsay SC, Cuscaden C. The current status of quantitative SPECT/CT in the assessment of transthyretin cardiac amyloidosis. J Nucl Cardiol. 2020;27(5):1464-8.

14. Masri A, Bukhari S, Eisele YS, Soman P. Molecular imaging of cardiac amyloidosis. J Nucl Med. 2020;61(7):965-70.

15. Dorbala S, Vangala D, Semer J, Strader C, Bruyere JR Jr, Di Carli MF, Moore SC, Falk RH. Imaging cardiac amyloidosis: a pilot study using ${ }^{18} \mathrm{~F}$-florbetapir positron emission tomography. Eur J Nucl Med Mol Imaging. 2014;41(9):1652-62

16. Minamimoto R, Awaya T, Iwama K, Hotta M, Nakajima K, Hirai R, Okazaki O, Hiroi Y. Significance of (11)C-PIB PET/CT in cardiac amyloidosis compared with (99m)Tc-aprotinin scintigraphy: a pilot study. J Nucl Cardiol. 2020;27(1):202-9.

17. Law WP, Wang WY, Moore PT, Mollee PN, Ng AC. Cardiac amyloid imaging with 18F-Florbetaben PET: a pilot study. J Nucl Med. 2016:57(11):1733-9.

18. Kircher M, Ihne S, Brumberg J, Morbach C, Knop S, Kortüm KM, Störk S, Buck AK, Reiter T, Bauer WR, et al. Detection of cardiac amyloidosis with 18F-Florbetaben-PET/CT in comparison to echocardiography, cardiac MRI and DPD-scintigraphy. Eur J Nucl Med Mol Imaging. 2019;46(7):1407-16

19. Zhao L, Tian Z, Fang Q. Diagnostic accuracy of cardiovascular magnetic resonance for patients with suspected cardiac amyloidosis: a systematic review and meta-analysis. BMC Cardiovasc Disord. 2016;16:129.

20. Wang TKM, Brizneda MV, Kwon DH, Popovic ZB, Flamm SD, Hanna M, Griffin BP, Xu B. Reference ranges, diagnostic and prognostic utility of native T1 mapping and extracellular volume for cardiac amyloidosis: a meta-analysis. J Magn Reson Imaging: JMRI. 2020;53(5):1458-68.

21. Pan JA, Kerwin MJ, Salerno M. Native T1 mapping, extracellular volume mapping, and late gadolinium enhancement in cardiac amyloidosis: a meta-analysis. JACC Cardiovasc Imaging. 2020;13(6):1299-310.

22. Kim YJ, Ha S, Kim Yl. Cardiac amyloidosis imaging with amyloid positron emission tomography: a systematic review and meta-analysis. J Nucl Cardiol. 2020;27(1):123-32.
23. Kim SH, Kim YS, Kim SJ. Diagnostic performance of PET for detection of cardiac amyloidosis: a systematic review and meta-analysis. J Cardiol. 2020;76(6):618-25.

24. Moher D, Liberati A, Tetzlaff J, Altman DG. Preferred reporting items for systematic reviews and meta-analyses: the PRISMA statement. Int I Surg (London, England). 2010;8(5):336-41.

25. Reitsma JB, Moons KG, Bossuyt PM, Linnet K. Systematic reviews of studies quantifying the accuracy of diagnostic tests and markers. Clin Chem. 2012;58(11):1534-45.

26. Cumpston M, Li T, Page MJ, Chandler J, Welch VA, Higgins JP, Thomas J. Updated guidance for trusted systematic reviews: a new edition of the Cochrane Handbook for Systematic Reviews of Interventions. Cochrane Database Syst Rev. 2019;10:Ed000142.

27. Deeks JJ, Macaskill P, Irwig L. The performance of tests of publication bias and other sample size effects in systematic reviews of diagnostic test accuracy was assessed. J Clin Epidemiol. 2005;58(9):882-93.

28. Cuddy S, Dorbala S, Di Carli MF. Imaging of cardiac amyloidosis: will this become a unique application for dual-isotope imaging? J Nucl Cardiol. 2020;27(1):38-40

29. Hotta M, Minamimoto R, Awaya T, Hiroe M, Okazaki O, Hiroi Y. Radionuclide imaging of cardiac amyloidosis and sarcoidosis: roles and characteristics of various tracers. Radiographics. 2020;40(7):2029-41.

30. From AM, Maleszewski JJ, Rihal CS. Current status of endomyocardial biopsy. Mayo Clin Proc. 2011;86(11):1095-102.

31. Donnelly JP, Hanna M. Cardiac amyloidosis: an update on diagnosis and treatment. Clevel Clin J Med. 2017;84(12 Suppl 3):12-26.

32. Siddigi OK, Ruberg FL. Cardiac amyloidosis: an update on pathophysiology, diagnosis, and treatment. Trends Cardiovasc Med. 2018;28(1):10-21.

33. Barbero U, Destefanis P, Pozzi R, Longo F, Piga A. Exercise stress echocardiography with tissue Doppler imaging (TDI) detects early systolic dysfunction in Beta-thalassemia major patients without cardiac iron overload. Mediterr J Hematol Infect Dis. 2012;4(1):12037.

34. Kyriakou P, Mouselimis D, Tsarouchas A, Rigopoulos A, Bakogiannis C, Noutsias M, Vassilikos V. Diagnosis of cardiac amyloidosis: a systematic review on the role of imaging and biomarkers. BMC Cardiovasc Disord. 2018;18(1):221.

35. Maurer MS, Ruberg FL, Weinsaft JW. More than meets the eye: time for a new imaging paradigm to test for cardiac amyloidosis. J Card Fail. 2018;24(2):87-9.

36. Vogelsberg H, Mahrholdt H, Deluigi CC, Yilmaz A, Kispert EM, Greulich S, Klingel K, Kandolf R, Sechtem U. Cardiovascular magnetic resonance in clinically suspected cardiac amyloidosis: noninvasive imaging compared to endomyocardial biopsy. J Am Coll Cardiol. 2008;51(10):1022-30.

37. Sperry BW, Burgett E, Bybee KA, McGhie Al, O'Keefe JH, Saeed IM, Thompson RC, Bateman TM. Technetium pyrophosphate nuclear scintigraphy for cardiac amyloidosis: Imaging at 1 vs 3 hours and planar vs SPECT/CT. J Nucl Cardiol. 2020;27(5):1802-7.

38. Malka N, Abulizi M, Kharoubi M, Oghina S, Galat A, Le Bras F, Moktefi A, Guendouz S, Molinier-Frenkel V, Fanen P, et al. Extracardiac soft tissue uptake, evidenced on early (99m)Tc-HMDP SPECT/CT, helps typing cardiac amyloidosis and demonstrates high prognostic value. Eur J Nucl Med Mol Imaging. 2020;47(10):2396-406.

39. Wollenweber T, Rettl R, Kretschmer-Chott E, Rasul S, Kulterer O, Rainer E, Raidl M, Schaffarich MP, Matschitsch S, Stadler M, et al. In vivo quantification of myocardial amyloid deposits in patients with suspected transthyretin-related amyloidosis (ATTR). J Clin Med. 2020;9(11):3446.

40. Zhang LX, Martineau P, Finnerty V, Giraldeau G, Parent MC, Harel F, Pelletier-Galarneau M. Comparison of 18F-sodium fluoride positron emission tomography imaging and 99mTc-pyrophosphate in cardiac amyloidosis. J Nucl Cardiol. 2020. https://doi.org/10.1007/s12350-020-02425-5.

41. Rosengren S, Skibsted Clemmensen T, Tolbod L, Granstam SO, Eiskjær H, Wikström G, Vedin O, Kero T, Lubberink M, Harms HJ, et al. Diagnostic accuracy of [(11)C]PIB positron emission tomography for detection of cardiac amyloidosis. JACC Cardiovasc Imaging. 2020;13(6):1337-47.

42. Papathanasiou M, Kessler L, Carpinteiro A, Hagenacker T, Nensa F, Umutlu L, Forsting M, Brainman A, Kleinschnitz C, Antoch G, et al. (18)F-flutemetamol positron emission tomography in cardiac amyloidosis. J Nucl Cardiol. 2020. https://doi.org/10.1007/s12350-020-02363-2.

43. Martinez-Naharro A, Baksi AJ, Hawkins PN, Fontana M. Diagnostic imaging of cardiac amyloidosis. Nat Rev Cardiol. 2020;17(7):413-26. 
44. Abulizi M, Sifaoui I, Wuliya-Gariepy M, Kharoubi M, Israël JM, Emsen B, Bodez D, Monnet A, Didierlaurent D, Tacher V, et al. (18)F-sodium fluoride PET/MRI myocardial imaging in patients with suspected cardiac amyloidosis. J Nucl Cardiol. 2019;28(4):1586-95.

45. Aquaro GD, Pugliese NR, Perfetto F, Cappelli F, Barison A, Masci PG, Passino C, Emdin M. Myocardial signal intensity decay after gadolinium injection: a fast and effective method for the diagnosis of cardiac amyloidosis. Int J Cardiovasc Imaging. 2014;30(6):1105-15.

46. Asif T, Gomez J, Singh V, Doukky R, Nedeltcheva A, Malhotra S. Comparison of planar with tomographic pyrophosphate scintigraphy for transthyretin cardiac amyloidosis: Perils and pitfalls. J Nucl Cardiol. 2020;28(1):104-11.

47. Awaya T, Minamimoto R, Iwama K, Kubota S, Hotta M, Hirai R, Yamamoto M, Okazaki O, Hara H, Hiroi Y, et al. Performance of (99m)Tc-aprotinin scintigraphy for diagnosing light chain (AL) cardiac amyloidosis confirmed by endomyocardial biopsy. J Nucl Cardiol. 2020;27(4):1145-53.

48. Baggiano A, Boldrini M, Martinez-Naharro A, Kotecha T, Petrie A, RezkT, Gritti M, Quarta C, Knight DS, Wechalekar AD, et al. Noncontrast magnetic resonance for the diagnosis of cardiac amyloidosis. JACC CardiovasC Imaging. 2020;13(1 Pt 1):69-80.

49. Baroni M, Nava S, Quattrocchi G, Milazzo A, Giannattasio C, Roghi A, Pedrotti P. Role of cardiovascular magnetic resonance in suspected cardiac amyloidosis: late gadolinium enhancement pattern as mortality predictor. Neth Heart J. 2018;26(1):34-40.

50. Bellevre D, Bailliez A, Delelis F, Blaire T, Agostini D, Mouquet F, Maréchaux S, Manrique A. Quantitation of myocardial (99m)Tc-HMDP uptake with new SPECT/CT cadmium zinc telluride (CZT) camera in patients with transthyretin-related cardiac amyloidosis: ready for clinical use? J Nucl Cardiol. 2020; https://doi.org/10.1007/s12350-020-02274-2.

51. Bhatti S, Watts E, Syed F, Vallurupalli S, Pandey T, Jambekar K, Mazur W, Hakeem A. Clinical and prognostic utility of cardiovascular magnetic resonance imaging in myeloma patients with suspected cardiac amyloidosis. Eur Heart J Cardiovasc Imaging. 2016;17(9):970-7.

52. Cappelli F, Gallini C, Di Mario C, Costanzo EN, Vaggelli L, Tutino F, Ciaccio A, Bartolini S, Angelotti P, Frusconi S, et al. Accuracy of 99mTc-Hydroxymethylene diphosphonate scintigraphy for diagnosis of transthyretin cardiac amyloidosis. J Nucl Cardiol. 2019;26(2):497-504.

53. Ezawa N, Katoh N, Oguchi K, Yoshinaga T, Yazaki M, Sekijima Y. Visualization of multiple organ amyloid involvement in systemic amyloidosis using (11)C-PiB PET imaging. Eur J Nucl Med Mol Imaging. 2018;45(3):452-61.

54. Flaherty KR, Morgenstern R, PozniakoffT, DeLuca A, Castano A, Maurer MS, Bokhari S. (99m)Technetium pyrophosphate scintigraphy with cadmium zinc telluride cameras is a highly sensitive and specific imaging modality to diagnose transthyretin cardiac amyloidosis. J Nucl Cardiol. 2020;27(2):371-80.

55. Gallini C, Tutino F, Martone R, Ciaccio A, Costanzo EN, Taborchi G, Morini S, Bartolini S, Farsetti S, Di Mario C, et al. Semi-quantitative indices of cardiac uptake in patients with suspected cardiac amyloidosis undergoing 99mTc-HMDP scintigraphy. J Nucl Cardiol. 2019.
56. Gillmore JD, Maurer MS, Falk RH, Merlini G, Damy T, Dispenzieri A, Wechalekar AD, Berk JL, Quarta CC, Grogan M, et al. Nonbiopsy diagnosis of cardiac transthyretin amyloidosis. Circulation. 2016;133(24):2404-12.

57. Karamitsos TD, Piechnik SK, Banypersad SM, Fontana M, Ntusi NB, Ferreira VM, Whelan CJ, Myerson SG, Robson MD, Hawkins PN, et al. Noncontrast T1 mapping for the diagnosis of cardiac amyloidosis. JACC CardiovasC Imaging. 2013;6(4):488-97.

58. Kircher M, Ihne S, Brumberg J, Morbach C, Knop S, Kortüm KM, Störk S, Buck AK, Reiter T, Bauer WR, et al. Detection of cardiac amyloidosis with (18)F-Florbetaben-PET/CT in comparison to echocardiography, cardiac MRI and DPD-scintigraphy. Eur J Nucl Med Mol Imaging. 2019:46(7):1407-16

59. Lee SP, Lee ES, Choi H, Im HJ, Koh Y, Lee MH, Kwon JH, Paeng JC, Kim HK, Cheon GJ, et al. 11C-Pittsburgh B PET imaging in cardiac amyloidosis. JACC Cardiovasc Imaging. 2015;8(1):50-9.

60. Martineau P, Finnerty V, Giraldeau G, Authier S, Harel F, Pelletier-Galarneau $\mathrm{M}$. Examining the sensitivity of $18 \mathrm{~F}-\mathrm{NaF}$ PET for the imaging of cardiac amyloidosis. J Nucl Cardiol. 2019;28(1):209-18.

61. Masri A, Bukhari S, Ahmad S, Nieves R, Eisele YS, Follansbee W, Brownell A, Wong TC, Schelbert E, Soman P. Efficient 1-hour technetium-99 m pyrophosphate imaging protocol for the diagnosis of transthyretin cardiac amyloidosis. Circ Cardiovasc Imaging. 2020;13(2):e010249.

62. Moore PT, Burrage MK, Mackenzie E, Law WP, Korczyk D, Mollee P. The utility of (99m)Tc-DPD scintigraphy in the diagnosis of cardiac amyloidosis: an Australian experience. Heart Lung Circ. 2017;26(11):1183-90.

63. Papantoniou V, Valsamaki P, Kastritis S, Tsiouris S, Delichas Z, Papantoniou Y, Tsiouma M, Athanasoulis T, Fotopoulos A, Dimopoulos MA. Imaging of cardiac amyloidosis by (99m)Tc-PYP scintigraphy. Hell J Nucl Med. 2015;18(Suppl 1):42-50

64. Poterucha TJ, Elias P, Bokhari S, Einstein AJ, DeLuca A, Kinkhabwala M, Johnson LL, Flaherty KR, Saith SE, Griffin JM, et al. Diagnosing transthyretin cardiac amyloidosis by technetium $99 \mathrm{~m}$ pyrophosphate: a test in evolution. JACC Cardiovasc Imaging. 2020;14(6):1221-31.

65. Rapezzi C, Quarta CC, Guidalotti PL, Pettinato C, Fanti S, Leone O, Ferlini A, Longhi S, Lorenzini M, Reggiani LB, et al. Role of (99m)Tc-DPD scintigraphy in diagnosis and prognosis of hereditary transthyretin-related cardiac amyloidosis. JACC Cardiovasc Imaging. 2011;4(6):659-70.

66. Régis C, Harel F, Martineau P, Grégoire J, Abikhzer G, Juneau D, PelletierGalarneau M. Tc-99m-pyrophosphate scintigraphy for the diagnosis of ATTR cardiac amyloidosis: comparison of quantitative and semi-quantitative approaches. J Nucl Cardiol. 2020;27(5):1808-15.

67. White JA, Kim HW, Shah D, Fine N, Kim KY, Wendell DC, Al-Jaroudi W, Parker M, Patel M, Gwadry-Sridhar F, et al. CMR imaging with rapid visual $\mathrm{T} 1$ assessment predicts mortality in patients suspected of cardiac amyloidosis. JACC Cardiovasc Imaging. 2014;7(2):143-56.

\section{Publisher's Note}

Springer Nature remains neutral with regard to jurisdictional claims in published maps and institutional affiliations.

\footnotetext{
Ready to submit your research? Choose BMC and benefit from:

- fast, convenient online submission

- thorough peer review by experienced researchers in your field

- rapid publication on acceptance

- support for research data, including large and complex data types

- gold Open Access which fosters wider collaboration and increased citations

- maximum visibility for your research: over 100M website views per year
}

At BMC, research is always in progress.

Learn more biomedcentral.com/submissions 